\title{
Some Reflections on the Future of Music Therapy in Nigeria Charles Onomudo Aluede
}

\begin{abstract}
This paper examines the present state of music therapy in Nigeria. In doing this, it discusses music therapy, the scope of operation and competence of the therapists, their trainings and dispositions. In the same vein, it examines the critical needs of the Nigerian music therapist in consonance with the people's beliefs. As a result of this, it advocates that the training of Nigerian music therapists should incorporate cultural realities of the people; that researches should be intensified, taken to higher heights; and that for their activities to be felt in Nigeria, they must function under a known and registered body. Whether music can really heal is not in doubt but convincing strides should be taken demonstrate it.
\end{abstract}

Key words: Music Therapy, Illness, Aetiology and disease

\section{Introduction}

In Nigeria, there exist different kinds of therapies out of which ethno-medical practices form the major bulk of it all. Surprisingly, the use of music in healing is one of such ethno-medical practices hence we often talk of ethno- music therapy. In the orthodox settings, music is also used for healing purposes. Therefore it is not out of place to hear in common and everyday English, terms like music in therapy, music as therapy or music therapy. Used in whichever way, it points to the therapeutic potency of music. Given this age old tradition of music in the restoration of health to man, can one sincerely say that in our present epoch, its use in healing has been standardised, accepted and not seen as an unfamiliar form of health care delivery? This scenario is what this paper intends to examine in great detail. When should this kind of therapy be advised? What is currently being done to have the field firmly rooted in our health 
care delivery? Do we have any known association in Nigeria? These myriads of questions require answers.

\section{What is music therapy?}

Quite frankly, a lot of work has been done on the formulation of a working definition that captures the essence of music therapy; some of these are Alvin (1975:4) where he opined that music therapy is the controlled use of music in the treatment, education, training and rehabilitation of children and adults suffering from physical, mental or emotional disorders. Bruscia (1998) defined music therapy as an interpersonal process in which the therapist uses music and all of its facts - physical emotional, mental, social, aesthetic, and spiritual to help clients to improve and maintain health. These definitions are apt in view of the intent of this essay.

\section{The scope and competence of music therapy}

The scope and competence of music therapy if put differently could be expressed thus: who needs the services of a music therapist? Or with whom is music therapist used? Music therapy is used with individuals of all ages and with a variety of conditions, including: psychiatric disorders, medical problems, physical handicaps, sensory impairments, developmental disabilities, substance abuse, communication disorders, interpersonal problems, and aging. It is also used to improve learning to build self esteem, to reduce stress, to support physical exercise and for a host of other health related activities (Bruscia, 1998:1)

\section{Where do they work?}

Music therapists work in general hospitals, schools, prisons, health centres, training institutions, psychiatric facilities, private practices and universities. 


\section{Why music therapy?}

Within and outside Africa, traditional healing has been practised as evidenced in the works of Oduyoye (1983) and Geber (2000) to mention just a few. Regrettably, only few works discussed music as an important source of healing. Early records on the use of music in healing include those from Israel, India, China, Greece, North and South America, Egypt and some African countries.

The Holy Bible provides information on how music was used in Israel. It gives an account of how God shared the entire land of Israel into eleven tribes, excluding the twelfth one - the Levites. The Levites were given the responsibility of living, serving and performing music in God's temples all over Israel. In return, they were fed by the other eleven tribes of Israel through the payment of tithes (Numbers 3: 6-8). That God assigned this role to the Levites brings to mind an institutionalized order of musical training. The Hebrews and the early Christians believed in the singing of psalms for healing: An example is the use of music performed on David's harp to calm the insanity of King Saul as recorded in the holy Bible (1 Samuel 16:23)

In China, a similar tradition of music healing exists. It was reported that schools came into being when the Chinese invention of writing penetrated into Egypt (Muir 1980). Reasoning ahead of their peers in terms of the development of music healing, the Chinese evolved the employment of vowels as an aspect of the healing process in which chants were involved. Discussing this idea further, McClellan (1988) says it is hardly a new idea; indeed, one of the earliest references came from Chinese healing practices. In the studies on Chinese music, postures for singing of vowels, the identification of the relationship between vowels and pitches to glands, and the effects of vowels on the whole body were developed. 
In Greece, there are so many legends on the supremacy and efficacy of music in healing. Orpheus was reported to have used his voice, which could alter the course of a river and secure the release of his dead wife from Hades (McClellan, 1988). It was also believed that through music, Odyssey was able to stop the flow of blood from Ulysses' wound (McClellan, 1988). The validations of these reports are outside the scope of this work but they informed us of how music was highly revered in Greece. The Greek mathematician, philosopher and physicist, Pythagoras freed the minds of his disciples from the day's cares by playing a kind of music to calm them down.

We have discussed music healing in Israel, China and Greece. In all, McClellan (1988) and Swami Prabhupada (1991) observe that nowhere in the world is the practice of music as a spiritual discipline more highly developed than in India where Mantra Yoga and Nada Yoga two forms of meditation are practised. The Indians believe that two types of music are used for spiritual purposes; one leads to a state of trance while the other leads to a meditative state. The music that leads to the state of trance is used for spiritual and healing purposes. In Hindu belief, chanting can be done in two ways: real chanting which is called kirtana and singing the mantras, which if sung devotedly makes the singer achieve physical and spiritual purity which in other words are physical \& emotional healing (Prabhupada, 1991).

There is a general agreement in the existence of a universal spirit force, which sustains and governs the universe. The Jews refer to this force as Yahweh, the Vedic tradition calls the force Prana while in Chinese tradition it is Chi. Adodo (2003) also suggested that Africans believe in the existence of mysterious forces which control human activities in this world and that the forces manifest in the form of spirits. According to him, "Africans believe that it is through the manipulation of sound that they link up with and use this force. Hence, great emphasis is placed on speech, incantations, singing and music all of which of course involve dance"' (Adodo, 2003: 50). 
The healing powers of music have become an ever-growing subject in academic discourse. Today, scholars are beginning to develop interest in the extra musical functions of music. Such interest has culminated in studies in music and healing (Omibiyi-Obidike 1998) as well as ethnomusic therapy (Moreno, 1995). Music healing among some ethnic groups in Nigeria has been studied by Lateef (1987) Omibiyi-Obidike (1998), Nzewi (2002) and Mereni (2004). Today the whole world is living under the threat of various diseases. Several efforts are being made around the world to cure these diseases and to bring them under control (Navneet, 2002).

To this end, man has evolved different kinds of therapeutic systems, out of which the most basic is the use of medicine. However, the medicines often used to treat these ailments have their associated side effects and some ailments still persist after the application of medicine. It was thus concluded that it is impossible to control diseases by mere medication. The use of music in healing which does not have any side effects was then acclaimed to be efficacious in healing. Cottrell (2002) confirms that "since the beginning of recorded history, music has played a significant role in the healing of human kind. Music and healing were communal activities that were natural to everyone". She opines that music nourishes us in ways we don't even realize. It inspires us, relaxes us and energizes us. In short, it heals us and keeps us well. It resides everywhere in our world.

\section{Who is a music therapist?}

It is a general opinion which is also supported by Bruscia (1998) that the person who makes himself available as a therapist is in effect a socially sanctioned healer who has been designated thus by virtue of his training and skills. The therapist is a professional who makes a commitment to help others in need of his expertise. From the definition above certain issues 
require immediate classifications, they are primarily, (a) the training of the therapist (b) His social acceptability (c) His professional alignment (d) His desire to help.

\section{(a.) The training of a music therapist.}

Beyond a degree or chains of higher degrees in music, music therapy is seen as a different field of specialty within musical studies. In the institutions where music therapy programmes are offered, taught courses and practicum are its major components. These programmes produce scholars with post graduate diplomas in music therapy and masters degree holders in music therapy. Once an attempt was made at post-graduate diploma in Remedial music at the university of Cape Town South Africa but in floundered since its graduates were not eligible for state registration with the Medical and Dental council (Pavlicevic,2002) From this experience it means such programmes must also be an admixture of music and biomedical courses or should tilt towards related medical courses to make it robust so that its products would be able to synergise with their contemporaries in other care giving or rehabilitative fields .

\section{(b) The music therapist's social acceptability}

The precursor of social acceptability is training and acquisition of skills. By this we mean for the therapist to be socially accepted or for the people to have confidence in what services he has to offer, he needs a background training attachment in the hospital. Just as gold is tested with fire, the hospital and the successful cases handled will sell the therapist. If skilled in the chosen field clients will begin to build some trust on the therapist. This kind of attachment and practice should at reasonable costs be devoid of medical jargons of carrying out a successful surgery yet the patient is dead. It should be a proactive one where the fruits of practice would be seen effortlessly. 


\section{(c ) Music therapist's professional Alignment}

No man is an island; the music therapist must of necessity share some affinity with his peers or contemporaries. This is done through the membership of registered professional bodies. These bodies obvious organise workshops, conferences and festivals from time to time so as to avail members of the recent developments in the field

\section{(d) The music therapist's desire to help clients}

Primum non cere- "above all do no harm": This is an accepted slogan among medical personnel. Music therapists should have genuine desire to assist clients to achieve good states of health but not to compound their problems. They should be are people of true intention to help others. Beyond training and social acceptability, innate desire to help others should be a major feature of the music therapist. Having identified the expected attributes of a music therapist, it is also considered vital to discuss what disease is with particular reference to Nigeria which people often referred to as clients suffer.

\section{What is Disease?}

"The loss of health due to the collapse, disruption, malfunctioning or deterioration of organismic structures or processes; any illness, sickness or malady of mind, body and spirit (Bruscia 1998: 60). Weil (1988:42) gives the etymology of disease when he says that it came from an old French word meaning: Lack of ease' and he concludes by saying disease is the absence of ease. While disease may be seen as out of tuneness with oneself as the definitions above depict, in African societies it is out of tuneness with oneself and one's environment. This is of course why Nzewi says :

The traditional African concept of illness reorganizes natural and supernatural causes, ordinarily co-acting, together. Ill health can 
manifest as malfunctioning physiology, mental spiritual disorder or unusual external misfortune. Illness may be self-generated (psychosomatic), others-engineered. Congenital or caused by foreign agents. Sickness is not always diagnosed as the malfunctioning of body parts or organs isolation, even though the seat of the sick-feeling may be located in a body part - external or internal sickness could be signs for something else positive or injurious, which is impending. When such as sign gets mistaken as ordinary sickness, or when it is ignore and unattended to. The person harbouring the sign may suffer permanent injury usually mental. (Nzewi,2002:2).

Nzewi's submission above takes us to the Nigerian concept of illness and its causation. In contemporary Nigeria, three basic religions are practised and these are traditional religion, Christian religion and Islamic religion. Discussing religious groups in Africa generally, Middleton (1981) observes that:

Roughly $50 \%$ of the African population follows traditional religious practices; some $25 \%$ are Muslims who follow the way of Islam and the remaining $25 \%$ are Christians including Roman Catholics, Protestants and members of African Independent Churches (Middleton 1981:410).

A major fact emerges from the foregoing which is that $50 \%$ of Africans are traditionalists while 50\% are not. However, Ohaeri (1988) observes that irrespective of religious inclination every African seeks help, advice and treatment once in life from unorthodox or the traditional healers. In this connection, Emeka (1988) noted that "most Africans tend to uphold two faiths - they maintain the Christian faith when life is gay and happy, but holds to the indigenous faith when the fundamentals of life are at stake" (1988:6).

Thus, the foregoing, Africans are said to be partly Christians, Moslems, and partly believers in traditional religion. When life is smooth they align with the church and during trials they seek help from traditional sources. Healey et al (1997) confirms this in the words of a Zairian poet :

O unhappy Christian Mass in the morning Witch Doctor in the evening Amulet in the pocket Scapular around the neck (Healey1997:294).

Today, most Nigerians claim Christianity but only very few are firmly rooted in the Christian faith without occasional membership in and worship of traditional religion.

\section{Illness and its Aetiology in Nigeria}


Fatokun (2004) observed that suffering, pains and diseases as physical ills affecting the wellbeing of man are, according to the Jews, punitive measures from God to man for his shortcomings or violation of divine rules. Sharing a similar view, Nabofa (1983) says:

Among the Urhobo, a perpetually recalcitrant person, within the family and society, is believed not to be saved by sacrifices from death penalties of the ancestors. Such a person must be withdrawn to Erivbin (hades) and also be punished there (Nabofa,1983:299).

This view portrays God as being the author of disease and is supported by the Holy Bible where it is said that God smites, wounds, makes alive and heals (Isaiah 19:22, Deuteronomy 32:29 and Acts of the Apostles 9:8, 17 and 18).

The concept of illness and what it is differs from one culture to another. Illness in the views of the people of Rivers and Cross River States of Nigeria is sharply different from orthodox medical concepts. In this culture area, young ladies are fattened prior to formal betrothal and so slightly obsessed ladies are adjudged to be living healthy lives whereas obesity among Euro-American women is regarded as an abnormal condition in their culture (Erinosho, 1998).

In Nigeria, disease is caused by more than one variable - microbes, germs and/or infections or hereditary factors but also complex of many and they are: psychological, medical, socioenvironmental and cultural variables. These views are supported by Ohaeri (1988), Osunwole (1990; 1996), Kongo (1997) and Erinosho (1998). Discussing specifically the Yoruba belief system of diseases causation, Odejide (1978) distinguishes three factors: natural, preternatural and supernatural factors. In his opinion, natural factors include bad odours and filthy or unsanitary conditions while preternatural factors include witchcraft and human curse because humans are involved in the acts. The supernatural factors are traceable to non-humans, such as spirits, ancestors and gods. Sharing some views on Malawians idea of disease causation, Friedson (1997) observes that among the Timbuka people of Malawi, God, spirits and witches are etiologic agents involved in an episode of illness. When a Timbuka says, an illness is from God, it is in the context of natural causation. God-caused illnesses are closest to western medical conception of natural causation. The two others are beyond physical where western medical practice can be helpful. 
Expressing a similar view, Osunwole (1996) opines that from available ethnographic accounts of some non-western cultures and his interactions with Nigerian healers, aetiology of disease is attributable to three variables in Africa, namely, natural, supernatural and mystical. Disease which occur naturally can result from one's interaction with the physical environment such as wounds sustained in the farm, wounds at home, polluted drinking water etc and illness that are genetically inherited e.g. mental disorder, leprosy and sexually transmitted diseases. He maintains further that naturally caused diseases are not difficult to manage. Supernaturally caused disease is related to problems caused by neglected gods, spirits and ancestors whose devotees have failed to accord them necessary rites, sacrifices and recognition. Mystical types of disease are caused by witchcraft, curses or oaths. For Example, among the Esan of Edo state, Nigeria, four classes of disease causation are discernible by both the healers and the generality of the people. These are:

1. Normal sickness, which is natural and very tractable. The ailments under this category are those contacted from poor living conditions, heredity and through sexual promiscuity. Thus, when it is said in Esan that $\underline{O}$ mue' mianmhen it means one has contacted disease. This sentence often refers to disease contacted via sexual route.

3. Sickness caused by ancestors, gods and spirits. This type of sickness is often contacted through neglect of ancestors, village gods, eating a totem animal, breaking binding rules, shrines, violation of a brother's wife, infidelity or wilful destruction of a relative's property.

4. Sickness carried over from past earth life. There is a general belief in Esan that when a spouse dies and is not mourned by the widow or widower or when one commits an unexposed crime before death, when he reincarnates he begins to suffer and he can only be cured by offering of sacrifices.

When examined critically, there is a general consensus that ill health can be caused by more than one variable. For example, going against the community's will through the eating 
forbidden food or fruits can result in an intractable fever and diarrhoea, violating a sister could result into having symptoms of mental disorder like feeling lonely in the midst of friends, being afraid to relate with people, feeling of being discussed behind, being always uneasy and tense. An attempt to treat such a case medically will end in futility if the ancestors or gods are not approached for appropriate remedies.

The question then arises: Does God have hands in sicknesses? It is generally agreed particularly among the Turkana of Kenya that "God sends and takes away diseases, but serious breaches of the community's mores like incest or failure in important ritual may cause him to strike the offender dead" (Mbiti 1970:81). Addressing a similar issue in Central Africa, Brandel (1961:23) says "the presence of illness or any other misfortune is never seen as a product of natural causes but always as a result of magic malevolence. Hence, the ceremonial observances as a kind of agent to stir up an invisible match between the forces of evil and good". Sharing the same opinion but using the Akan of Ghana as a case in point, Appiah-Kubi (1983:263) observes that, "illness on the other hand shows that one has fallen out of delicate balance. This is normally attributed to the breaking of taboo". Traditional Africa recognizes that when the environment is sick, diseases are prevalent and when the environment is rehabilitated, human health becomes secure (Nzewi 2002). He asserts further that traditional African concept of illness recognizes natural and supernatural causes ordinarily co-acting together. Hence, the maxim that "when herbs fail, heal the spirit" Nzewi (2002:2).

To further buttress this co-acting nature of causal factors in disease diagnosis, Janzen (1978) talks about a phenomenon in Zaire that:

When an affliction deteriorates almost to the level of incurability, there is a suspicion that spirits or human agency may be involved (Janzen 1978:77).

The general question usually asked is: Why am I sick and not any other person? This is where the roles of cults, ancestors and religious groups begin. The belief is that if one is in good relationship with his ancestors, they would protect him from all forms of negativity. But if one fails to carry out his obligations faithfully, they would abandon him and expose him to 
all forms of vicissitudes of life (Nabofa 1996). Osunwole (1996) discusses traditional classificatory systems in which misfortune is seen as health problem. He says problems like bankruptcy, failure in marriage, business, politics and administration may cause imbalance between body and soul that can result in sickness.

Nabofa (1996) and Friedson (1997) discuss initiatory sickness or illness. In their view, potential priests, priestesses and mediums of various ancestral cults and shrines fall sick as (a) temporal signs that they have been chosen and in such a state make utterances of relevance. (b) In a sick state they may be taken to a master healer who confirms the cause of such sickness and the mission of the sick person (c) or having heard the call to service at any given shrine as a priest tries to conceal it and attempts to go into other careers as a way of suppressing the call. Attesting to this fact, Nzewi (2002) remarks that:

In some African cultures, a person who will eventually become a healer is supernaturally selected through signs such as sickness. The signs which often result in strange behaviour or physiological ill health, manifests irrespective of ... age and gender. When diagnosed, preparing or capacitating the person to become a healer could entail the medico-musical theatre of "opening the inner eyes" (to receive beyond the commonly visible) or the "reception of extraordinary communications" (from the supernatural forces) (Nzewi, 2002: 2).

With these belief patterns in Nigeria, how then should the Nigerian music therapist be equipped or trained? The response below may be of some help in finding solutions to the myriads of issues raised.

\section{The future of music therapy in Nigeria}

In what follows below, this paper examines what appears to be this author's concerns about music therapy in Nigeria and they are: the need for an ideal nomenclature, the training of 
music therapists, and the need for researches and professional memberships to mention but a few.

\section{The Need for an Ideal Nomenclature}

Music therapy in Africa in general and Nigeria in particular has been closely knitted with religious practices. This is why one can easily see the different shades of African music performing healing functions. Just as African music is impure and collective so are its functions. Reporting Meki; Pacelivlic (2002:1) says that music in Africa is healing and what is music therapy other than some colonial import? Why is music therapy separate from music - making? Why is it calling itself thus in South Africa, instead of imbibing African music healing tradition. The views above are encapsulating and they remain the core zones which this segment will build on.

In African music, there is music healing or music therapy. This has been reported among the Xhosas of South Africa by Scott (2004) In Malawi by Friedson (1998), in Congo by Kongo (1997) and in Nigeria by Omibiyi-Obidike (1998) Mereni (2004) and Aluede (2008). As it is in Africa, Nigeria recognises more than a variable in disease causation. Music therapy as a general nomenclature is not bad but if the name is to be adopted in Nigeria, its scope must be enlarged to entail culture cum clinical approaches. In Nigeria, there are some forms of musical retreats to cleanse the land and strengthen its dwellers. This action is seen as prophylactic treatment for inhabitants of a particular locale. Examples of such ritual- musical intervention are found in Odegbigba ritual in Awankere festival of Warri and Agba Kuro ritual cleansing of Asaba town in Ichulor festival of Asaba people in Delta states. Sharing a similar opinion, Nzewi (2004:2) remarks that:

Preventive health includes scheduled and mandatory environmental cleaning avoidance rites to ward of evil forces (human and of spirit mien), as well as constant musical arts theatre that coerces mass participation, annual group spirit purgation music- drama (New Year rites, compound hygiene etc.) 


\section{The Need for the Training of the Music Therapist}

The quest for an acceptable nomenclature of what music healing should be called in Nigeria and the need for the training of the music therapist will be major determinants in the definition and development of the curriculum for the training of the individuals who will function in the society. Beyond the courses in theories of sound and healing, practicum in general hospitals, prison, teaching hospitals, psychiatric facilities to mention but a few, courses in ethno medical ethno psychology and ethno therapy are very important because “biomedicine does not contain culture free clinical realities” (Klainman,1978:91).

If there has been a group of Nigerians who studied music therapy overseas, the onus is on them to fashion out the real needs of the student therapist. The said real needs should embrace the cultural realities of the people the music therapist is to serve. Human resources application demands the evolution of culturally relevant models of training. This aim has become very vital because of palpable lapses/differences in western/African ideas of disease causation if put side by side. To conclude this segment, the observation of Alain Danielon is very informative and he said:

Almost the whole of Western terminology in Africa, almost the approaches, whether the intention behind them was good or evil, almost all the efforts made to take an interest in African countries so as to "help" them in their "development", have in many fields completely ignored or by passed the historical and cultural realities (Danielon,1970: 52).

\section{The Need for Collaborative Research in Music Therapy}

If music for therapy is to gain status as a profession, one of its greatest needs is the carrying out of significant researches (Folsom, 1968:36). There is an urgent need for aggressive researches in music therapy. This need must absolve interested scholars from closely related fields especially those keenly interested in understanding the philosophical principles of 
music therapy in the first case, after which an interdisciplinary approach to music therapy should be embarked upon in Nigeria.

To however avoid shadow boxing, duplication of efforts and unnecessary parallelism in researches, every music therapist should endeavour to be information communication technology (ICT) compliant. If individual break through are hoisted on the net, other potential researchers will be abreast with the work so far done, what stage we are and what has been undone. These will help in the formation of theoretical framework, enrich literature review and aid easy statement of problem in researchers. In a symposium on Nigeria traditional music held at the institute of African studies, university of Ibadan in 1976, Elder presented a paper christened "African traditional music and Ritual healing: a matter for serious research". If one may ask: How much research has been done in this area? In 2008, this author did some work of the bibliography resources on music therapy in Nigeria, what he found was surprisingly very few. To end this section, it should be said that to attest to the therapeutic potency of music is important but to carry out researches to substantiate the therapeutic potency of music in Nigeria is more important thus research in this direction is a sine qua non in this direction.

\section{The Need for Professional Registration of Nigerian Music Therapists}

$A b$ initio in this paper, a painstaking attempt has been made to put in sequence ideas or thoughts so that one idea will effortlessly flow into the other. In looking at the future of music therapy, search for an ideal nomenclature, training of therapists, collaborative researches have been ordered to lead us to our present destination. This said sequence will be unimportant if there is no professional body to regulate or moderate the activities of practitioners, aside regulation of activities, the professional body should strive to assume a status as high as the Nigeria medical or Dental association. This body should have a directory of all its members 
and area of specialty, identify the latest trends and techniques in the field and also share with its members through seminars, workshops and conferences as often found with most professional bodies. Provisions should also be made for professional members, student members, enthusiasts and patrons to take part and gain from its activities.

Examining the state of Music and Dance therapy in Nigeria, Aluede and Iyeh (2008) advocated the formulation of substantive healing theories of and practice in music/dance therapy, government support in the design of curriculum for training potential music therapists and establishment of centres or institutes for music therapy. However, we must be seen to have started something before looking for government, and private and public sector assistance. Music scholars, music therapists, ethnomusicologists and music educator in Nigeria must first of all put their house in order and do a redefinition of focus as far as the use of music for healing is concerned in Nigeria.

\section{Conclusion}

This paper has been concerned among other things, to eschew cursory conclusion in all the areas discussed. As a result of this, it covers in detail what music therapy is, where music therapists are needed, their training and disposition. In the same vein, it concludes advocating that the training of Nigerian music therapists should incorporate cultural realities of the people, that researches should be intensified and taken to higher heights and that for their activities to be palpated in Nigeria, they must function under a known and registered body. Whether music can really heal is not in doubt but convincing strides should be taken demonstrate it.

\section{References}

Adodo, A. 2003. The Healing Radiance of the Soul. Lagos: Agelex Publications. 
Aluede, Charles O. \& Iyeh, M. A. (2008). "Music and Dance Therapy in Nigeria: The Task before the Potential Nigerian Music Therapists in the Twenty First Century". Voices: A World Forum for Music Therapy. Retrieved April 28, 2009, from http://www.voices.no/mainissues/mi40008000257.php

Alvin, J. (1975). Music Therapy. London: Hut Chinson.

Brandel, R. 1961. The Music of Central Africa: An Ethnomusicological Study. The Hague: Mantins Nighoff.

Bruscia, K.E.( 1983) Defining music therapy Spring unity PA: spring House Books

Bruscia, K.E. 1993. Music Therapy: Answers to Most Common Questions. Spring City P.A: Spring House Books.

Cottrell, A. (2002). What is healing music? http://www.healingmusic.org/ Review 2005.

Danielou, A. "The musical languages of Black Africa" African music meeting held in Yaounde Cameroon between 23 - 27 February, 1970 organised by Unesco.

Elder, J.D. 1976. African Traditional Music and Ritual Healing: A matter for serious research. Symposium on Nigerian Traditional Music. Institute of African studies. University of Ibadan.

Emeka, O. 1988. "The Quest Means and Relevance of Africa Christian theology". African Christian Studies. 4. (3): 6-19.

Erinosho, O.A. 1998. Health Sociology for University, Colleges and Heath related Institution. Ibadan: Sam Bookman Educational and Commercial Services.

Fatokun, S.A. 2004. God "A Medicine - Man" A Historical Appraisal of Christianity and Medicine from the Ancient Times to Date. Lambert Eradiri: A legend in the Oasis of the Niger. Ed.Egbe Ifie. Ibadan: Oputoru Books.

Folsom, G.S. (1968) "Development of music therapy in the community: Developing the situation”, In E.T. Gaston (Ed) Music in Therapy Pp350 -363

Friedson, S. 1996. Dancing Prophets, Chicago: Chicago University Press. Funes, D.J. 1992. Musical Involvement. New York: Harcourt Brace.

Geber, R.2000. Vibrational Medicine for the $21^{\text {st }}$ Century. New York: Harper Collins ublishers.

Healey, J. and Syberts, D. 1997. Towards an African Narrative Theology. Nairobi, Kenya. Paulines Publication Africa.

Kleinman, A. (1978) "Concepts and model for the comparism of medical systems as culture system” Social Science and medicine Vol. 12, 85 - 93

Kongo P. Z.1997. Music and Healing in Kongo Area. Western central Africa. Conference Paper. International Centre for African Music and Dance. University of Ghana. Sept. 3-5 1997.

Lateef, Y. 1989. Hausa Performing Arts and Music. Lagos: Federal Ministry of Information and Culture.

Mbiti, J.S. 1992. African Religion and Philosophy. New York: Barnes and Noble Publishers. 
McClellan, R.1988 The Healing forces of Music. New York: Amity House Publishers.

Mereni, A.E. 2004. Music Therapy, concept scope and Competence. Lagos: Apex Books Limited.

Mereni, A.E.. 2004. Music Therapy in Medical History. Lagos. Apex Books Limited.

Moreno, J. J. 1995. Ethnomusic Therapy: An Interdisciplinary Approach to Music and Healing. The Arts in Psychotherapy. 22 (4):329 - 338.

Muir, F. 1980. The Frank Muir Book. London: Transworld Publisher Ltd.

Nabofa, M.Y. 1983. Erhi and Eschatology. Traditional Religion in West Africa. Ed. Ade Adegbola. Ibadan: Daystar Press.

Nabofa, M.Y. 1996. "Faith/Spiritual Healers as Alternative Therapeutics: Success and failures". Readings in Medical Sociology. Eds. Oke, E.O and Owumi, E.O. Ibadan: Resource Development and Management Services. 234-266.

Navneet, S. (2002). Auto urine therapy. Delhi: Paulist Press.

Nzewi, M. 2002. "Backcloth to Music and Healing in Traditional African Society". Voices. 2.(1): $1-4$.

Oduyoye, M.C. 1983. "Man's Self and The Spiritual Double”. Traditional Religion of West Africa, Ed. A. Adegbola. Ibadan: Daystar Press.

Ohaeri, J.U. 1988. “African Traditional Medicine: A Stage in the People's History". African Notes. 12. (1x2): 24-28.

Omibiyi-Obidike, M.A. 1997. "Music and Healing Among the Yoruba".African Notes. 22 $(1 \times 2): 1-53$.

Osunwole, S.A.1996. "Disease Diagnosis and Etiology as a System of Thought". Readings in Medical Sociology. Eds. E.O.Oke, and E.O. Owumi. Ibadan: Resource Development and Management Services.

Pavlicevic, M. 2001. Music Therapy in South Africa Compromise as Synthesis? Voices 1 (1): $1-2$.

Prabhupada, A.C. 1991. A Second Chance. London: The Bhaktivedan Book Trust.

Schwartz S. (2004) "Ngoma: Xhsas's Music therapy”. Retrieved July 23 ${ }^{\text {rd }}, 2005$ from www.healing music.org.

Tucek, G. (2006) "Traditional oriental music therapy - a regulatory and Rational approach" Music therapy today. Vol. VII, 3623647. 